\title{
Comparative analysis of health-related physical fitness levels among the young male workers performing sedentary and heavy occupational physical activity
}

\section{Prachi Patel ${ }^{*}$ and Rauf Iqbal}

\author{
Industrial Engineering and Manufacturing Systems, \\ NITIE, \\ Mumbai, India \\ Email: praachee1509@gmail.com \\ Email: rauf.nitie@gmail.com \\ *Corresponding author
}

\begin{abstract}
Study aimed to compare the health-related physical fitness levels (HRPF) among young male workers from physically active and inactive occupation. Ninety four healthy male workers (18-30 years) were selected from 2 distinct occupational group, i.e., office $(n=46)$ and construction $(\mathrm{n}=48)$. Constructions workers had significantly lower $(\mathrm{p}<0.001)$ BMI, fat $\%$, metabolic age (years), waist and hip circumference; and significantly higher $(\mathrm{p}<0.001)$ body water $\%$ and lean body mass $\%$ as compared to office workers. Therefore, construction workers had superior back flexibility, trunk lift scores and aerobic capacity. Whereas, office workers showed significantly good performance only in hand strength. No significant difference was found for strength (pinch, explosive leg and back) and endurance (upper and core body) tests. Occupational physical activity (OPA) significantly influences the body composition, flexibility and aerobic capacity. Whereas, lack of OPA can be associated with increase in obesity, larger waist and hip circumference; and poor performance in most of the fitness test.
\end{abstract}

Keywords: physical activity; PA; sedentary and heavy work; office workers; construction workers; health-related physical fitness; HRPF.

Reference to this paper should be made as follows: Patel, P. and Iqbal, R. (2020) 'Comparative analysis of health-related physical fitness levels among the young male workers performing sedentary and heavy occupational physical activity', Int. J. Forensic Engineering and Management, Vol. 1, No. 1, pp.62-75.

Biographical notes: Prachi Patel is presently a Fellow PhD scholar of the NITIE, Mumbai. She completed her Graduation in Interior Designing and Masters in Resource Management with specialisation in Ergonomics from the SNDT Women's University, Mumbai. She is teaching at undergraduate and postgraduate levels for past $51 / 2$ years. Furthermore, she has participated in many international and national conferences, training programs and workshops.

Rauf Iqbal completed his Masters in Human Physiology with specialisation in Ergonomics and Work Physiology, and accomplished his PhD from the Vidyasagar University, West Bengal, India. His area of expertise is ergonomics and human factors engineering. He has guided research students for Masters and $\mathrm{PhD}$ thesis and has many publications under his name. Moreover, he has participated in many international and national conferences, and also organised 
international conferences, seminars and workshops. Also, he has been carrying out consultancy studies in various industries in the area of ergonomics and work system design and is a member of several committees and associations.

This paper is a revised and expanded version of a paper entitled 'Health related physical fitness levels among the male workers performing moderate and heavy physical activity' presented at 15th International HWWE Conference (Humanizing Work and Work Environment), Aligarh Muslim University, Aligarh, India, 8th-10th December 2017.

\section{Introduction}

Physical fitness and health lifestyle habits have been reported to lower the risk of death from disease, foster healthy muscles, joints and bones, and enhance personal function and mental health (Voit, 2001). Many employment situations require workers to be physically 'strong' and 'fit' as they are capable of performing more physically demanding work without getting much tired. Physical fitness requirements are critical to the employment process and cannot be compromised (Stamford, 2003). Physical fitness remains a key requirement for good health among the general population although its assessment could be marred by various factors (Bello et al., 2016).

Health-related fitness (HRF) [also termed as health-related physical fitness (HRPF)] means the ability to perform daily activities with energy characteristics and capacities that are associated with a lower risk for developing chronic disease and premature death (Cvejic et al., 2013). HRF directly depends on the level of physical activity of the individual (Ruiz et al., 2009) and healthy diet (Kaasalainen et al., 2013).

In recent years, the world has seen a decline in the amount of physical activity being undertaken in each age group. Increased computerisation and mechanisation as well as convenient transportation lead to an increasingly sedentary lifestyle, which tends to reduce workers' daily physical activity (Huang et al., 2017). This situation is conducive to the development of many metabolic diseases from an early age due to the accumulation of excess adipose tissue, particularly in the visceral area (Kopiczko and Bogucka, 2018). Only one-half of working-aged (18-64 years) men in Europe are sufficiently active (Hallal et al., 2012) and up to $70 \%$ are overweight or obese (World Health Organisation, 2010). The decreasing trend in PA and increasing obesity among working-aged men are public health issues (Hallal et al., 2012). Finnish studies have also expressed concern about poor cardio respiratory fitness in young and working-aged men (Huotari, 2012). One of the most feasible explanations for this phenomenon consists in the decline of fitness, produced primarily by decreases in physical activity levels (Hill and Melanson, 1999).

Tests on five components of HRF (Caspersen et al., 1985) can help understand the general fitness levels of the workers performing physical work of different intensity. Society is changing in a way that values quality of life rather than focusing only on improving productivity (Shin et al., 2012), but in Indian scenario productivity is still a priority than health and quality of life.

One of the study by Anjana et al. (2014), to assess physical activity patterns across India shows that $54.4 \%$ adults were inactive while $31.9 \%$ were active and $13.7 \%$ were 
highly active. Subjects were more inactive in urban areas as compared to rural. Subjects spent more active minutes at work than in the commuting and recreation domains. Thus, the study shows that a large percentage of people in India are inactive with fewer than $10 \%$ engaging in recreational physical activity. Luzak et al. (2017) also stated that most of the time of German adults spent time in sedentarism (median 61\%/day) and only 14\% adhered to the WHO recommendation of 2.5 hours of moderate-vigorous physical activity per week for at least ten minute bouts.

Although many studies on occupational health and fitness are being conducted in western countries, there are not many in Indian context. As PA of adults in urban cities of India is declining and people spent active time majorly when at work; therefore, it seems obligatory to study the HRF levels among the workers from two distinct occupations having varying levels of physical activity. The main aim is to find out the variance in the HRF levels among sedentary and heavy workers due to their involvement in divergent occupational physical activity (OPA).

\section{Methods}

To measure the HRF levels, 94 healthy male workers, age 18-30 years from Maharashtra and Gujarat were selected. Workers performing office and computer related sitting work was considered as sedentary/light PA group; whereas, the workers from the construction industry were chosen as heavy PA group. A sample of 46 office workers and 48 construction workers were examined using on five components of HRF (Caspersen et al., 1985) using 13 tests adopted from fitness batteries like FITNESSGRAM ${ }^{\circledR}$ by The Cooper Institute (Plowman and Meredith, 2013), ALPHA test battery (Suni et al., 2009) and Total Physical Fitness Program, Kerala (Ministry of Youth Affairs \& Sports, 2012).

All the participants were contacted and the aims of the study were explained to them. Each participant gave written informed consent prior to the commencement. Information regarding their background, general health problems, and daily involvement in various type of physical activity (not presented in current paper) was recorded on a data capturing form. The pattern of engagement in different type of physical activity per week was determined on recall by the participants and observation at their workplace. Precise physical measurements on five components of HRF were taken for each of the workers after filling the above data.

\subsection{Tests for assessing five components of HRF}

\subsubsection{Body composition}

Stature height was measured in centimetres using anthropometer. Body weight $(\mathrm{kg})$, body fat ( $\%$ and weight), metabolic age (years), and body water content $(\%)$ was measured using Tanita BIA scale. BMI was computed [weight $(\mathrm{kg}) /$ height squared $\left(\mathrm{m}^{2}\right)$ ] to classify participants into different categories (i.e., $<18.5$ - underweight, 18.5 to $24.9-$ normal weight, 25 to 29.9 - overweight and $>30$ - obese). Lean body mass (LBM) (\% and weight) was computed by deducting the fat weight $(\mathrm{kg})$ from the body weight $(\mathrm{kg})$. Waist and hip circumference were measured. Waist hip ratio (WHR) was calculated [waist / hip] and workers were classified as $<0.85$ - excellent, 0.85-0.89 good, 0.90-0.95 average, $>0.95$ at risk (Bray and Gray, 1988). 


\subsubsection{Muscular strength}

Pinch grip strength (tip, palmar and key pinch) and hand grip (right and left) were measured using Jamar dynamometer and maximum score (in $\mathrm{kg} /$ force) was recorded. Back muscle strength was measured using back leg dynamometer and maximum score (kg/force) was documented. Explosive strength of legs was measured by standing high jump test (in inch) where initial reach was subtracted by maximum reach.

\subsubsection{Muscular endurance}

Dynamic core endurance of abdominal muscles was measured with sit-ups/min (hands crossed on chest). Upper body endurance was measured with full body push-up/min. Trunk lift test was used to measure the static trunk extension endurance of the back (inch).

\subsubsection{Flexibility}

Low back flexibility was recorded by sit and reach (SAR) test using a 12 inch high fabricated box with 15 inch as starting point at feet level (Cooper Institute, 2006). Participants were made to sit on exercise mats with the back at $90^{\circ}$ and their feet stretched out straight against the SAR box. The upper limbs were fully extended with hands superimposed. They were asked to stretch and slide gradually forward in a straight direction on the reach box. The total exertion made was recorded at tips of the middle fingers as the SAR distance (inch).

For shoulder flexibility test, participants had to touch the fingers behind the back. If fingers overlapped they were graded as 'very good', fingertips just touching as 'good' and fingertips not touching as 'poor'.

\subsubsection{Aerobic fitness}

It was measured using Queens College step test (stool height of $41.3 \mathrm{~cm}$ and metronome setting at 96 beats/mins). They were required to step-up and step-down on the bench at a steady pace of 24 beats per minute. Participants were asked to stop at the expiration of 3 $\min$. The recovery heart rate was measured immediately after the test in sitting position for 15 seconds. $\mathrm{VO}_{2} \max (\mathrm{ml} / \mathrm{kg} / \mathrm{min})$ was calculated (McArdle et al., 1972).

\subsection{Data analysis}

Data was analysed using the Software Statistical Package for Social Sciences (SPSS) version 20.0. Descriptive statistics for mean, standard deviation and range were employed to summarise the data. Unpaired sample t-test was used to determine the differences in means of the five components of physical fitness between the two independent groups of office and construction workers (level of significance $\mathrm{p}<0.05$ ). 


\section{Results}

Office workers $(n=46)$ were mostly engineers, project interns, account personnel, managers, supervisors, expiry date checker and AutoCAD drafting person. These workers were mostly involved in sedentary/light work with sitting on computers as an important work task. They were mostly having a fixed desk to work on computer or do paper work with sometime light to moderate walking at workplace/work site. On the other hand, the construction workers $(n=48)$ included all those who were involved in performing work at any construction site like masons, carpenters, false ceiling workers, electricians, welder and manual labour. They were involved in performing variety of moderate to heavy strenuous activities, assuming different work postures and lifting loads at workplace on day-to-day basis. They had to climb stairs/ladder/scaffolding, use different work tools, do pushing/pulling, walking/climbing with loads, and perform hand related tasks throughout their work timing except for breaks.

From Table 1, it can be seen that the mean age \pm SD (yrs) of the office workers $(24.8 \pm 2.5)$ was more than the construction workers $(21.9 \pm 3.5)$. Office workers were more educated (average of $15.74 \pm 2.27$ grade), as compared to the construction workers $(6.48 \pm 3.97$ grade). Thus, the age to join for office work was delayed as against the construction work, which was started from a very young age. Therefore, the average work experience (yrs) of the construction workers (5.52 \pm 4.24 yrs) was also found to significantly more as compared to the office group (2.50 \pm 2.36$)$. The average monthly income $(23,749 \mathrm{INR} /$ month) of the office workers was significantly more against the construction workers $(14,636 \mathrm{INR} /$ month); as most of them have achieved higher education and thus had better monthly salary. Even though both the group performed dissimilar intensity of physical activity at work; still, the RPE rating (rate of perceived exertion using Borg's scale ranging from 6 to 20) for the occupational activities performed by them at work, was not significantly different $(p>0.05)$, with both groups having means RPE score of 10.97 and 11.73 , respectively.

It is observed from Table 2, that the mean height, weight and the average BMI scores of the office workers was significantly more (mean height $=169.6 \mathrm{~cm}$, mean weight $=$ $70.9 \mathrm{~kg}$ and mean $\mathrm{BMI}=24.6$ ) than the construction workers (mean height $=160.4 \mathrm{~cm}$, mean weight $=50.7 \mathrm{~kg}$ and mean $\mathrm{BMI}=19.7)$ with $\mathrm{p}<0.001$. Body fat $\%$ $(\overline{\mathrm{x}} \pm \mathrm{SD}=22.3 \pm 6.0)$, fat weight $(\mathrm{kgs})(\overline{\mathrm{x}} \pm \mathrm{SD}=16.5 \pm 6.9)$ and metabolic age (yrs) $(\overline{\mathrm{x}} \pm \mathrm{SD}=32.5 \pm 11.6)$ were found to be significantly more $(\mathrm{p}<0.001)$ among the office workers. $\mathrm{LBM} /$ fat free mass $(\mathrm{kgs})$ was more $(\overline{\mathrm{x}} \pm \mathrm{SD}=54.4 \pm 6.6)$ among the office workers; but LBM \% [(LBM $(\mathrm{kg}) /$ body weight $(\mathrm{kg}) * 100)]$ was less among the office workers $(\overline{\mathrm{x}} \pm \mathrm{SD}=77.7 \pm 6.0) \quad$ as compared to the construction groups $(\overline{\mathrm{x}} \pm \mathrm{SD}=88.3 \pm 5.5)$. It is therefore, very clear that the body weight and BMI of office workers was significantly higher $(\mathrm{p}<0.001)$ due to more of fat \% and less of LBM $\%$ (Figures 1 and 2). Even the average metabolic age was significantly higher than their actual chronological age among the office workers; whereas, it was significantly less among the construction workers. All these are the chief indicator of poor health among the office workers as compared to the construction group. 
Figure 1 Classification of workers with respect to BMI scores (see online version for colours)

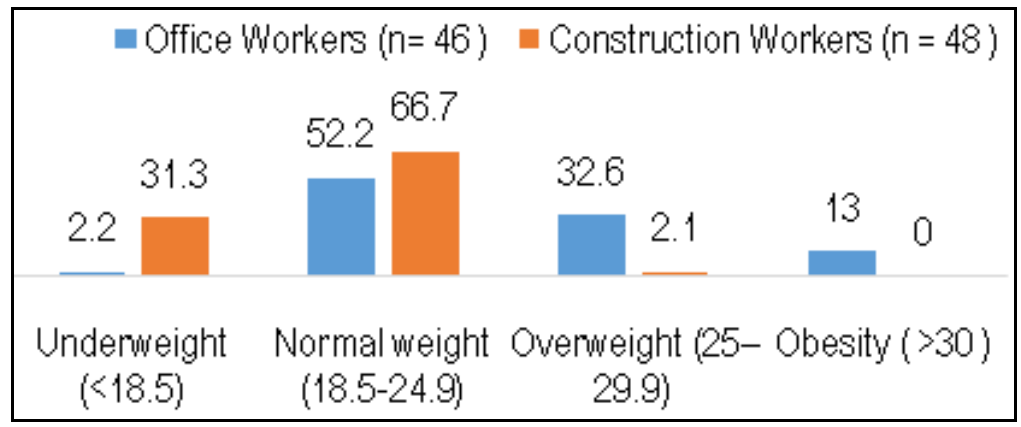

Figure 2 Classification of workers with respect to fat \% (see online version for colours)

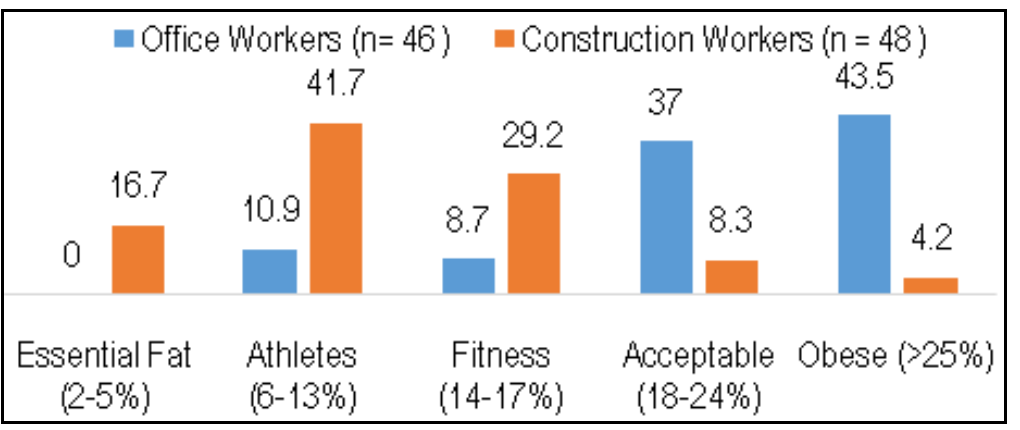

In contrast, the construction workers had significantly higher $(\mathrm{p}<0.001)$ body water $\%$ $(\overline{\mathrm{x}} \pm \mathrm{SD}=58.0 \pm 4.8)$ and LBM \% $(\overline{\mathrm{x}} \pm \mathrm{SD}=88.3 \pm 5.5)$ with least body fat $\%(\overline{\mathrm{x}} \pm \mathrm{SD}=$ 11.7 \pm 5.5 ). These are an essential factor for lesser weight, BMI, metabolic age (yrs) $(\overline{\mathrm{x}} \pm \mathrm{SD}=18.0 \pm 5.6)$ and superior $\mathrm{VO}_{2}$ max among the construction workers as against the office workers (Table 2).

With respect to average waist and hip circumference (Table 2), the office workers had significantly higher $(\mathrm{p}<0.001)$ circumference at waist $(87.3 \mathrm{cms})$ and hip $(100.6 \%)$, thus indicating more of fat deposition at waist and hip as compared to construction workers (waist - $70.7 \mathrm{cms}$, hip - $84.0 \mathrm{cms}$ ). Waist circumference was divided by the hip circumference to calculate the WHR. The mean WHR scores of the office workers were also found to be significantly higher $(\mathrm{p}<0.05)$ as compared to construction workers, thus indicating more risk among the office group.

From Table 3, it can be observed that the average Hand grip strength ( $35.8 \mathrm{~kg} /$ force) was significantly more $(\mathrm{p}<0.05)$ among the office workers than the construction group $(32.0 \mathrm{~kg} /$ force) and this could be attributed to more of LBM weight $(\mathrm{kg})$ among the office workers which enabled them to exert more of static strength as compared to the construction workers. 
Table 1 Sample characteristics according to the non-active and active occupation

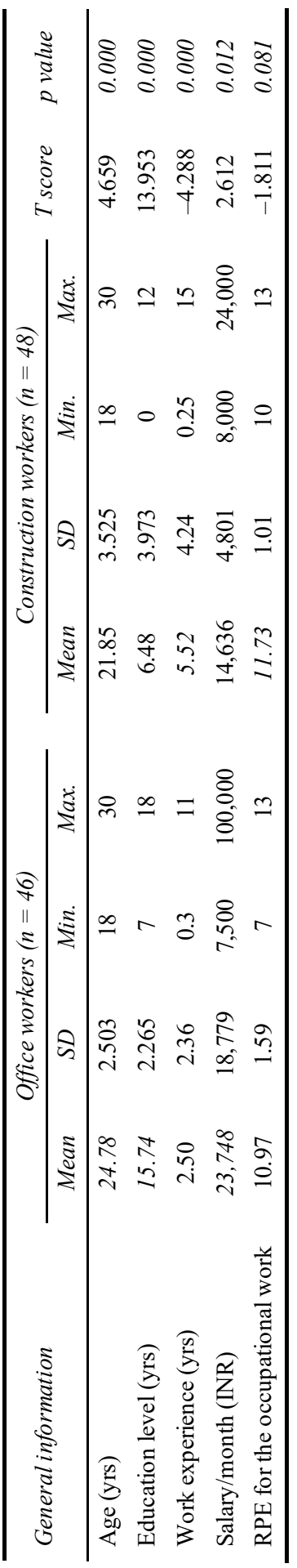


Table 2 Body composition scores of the workers

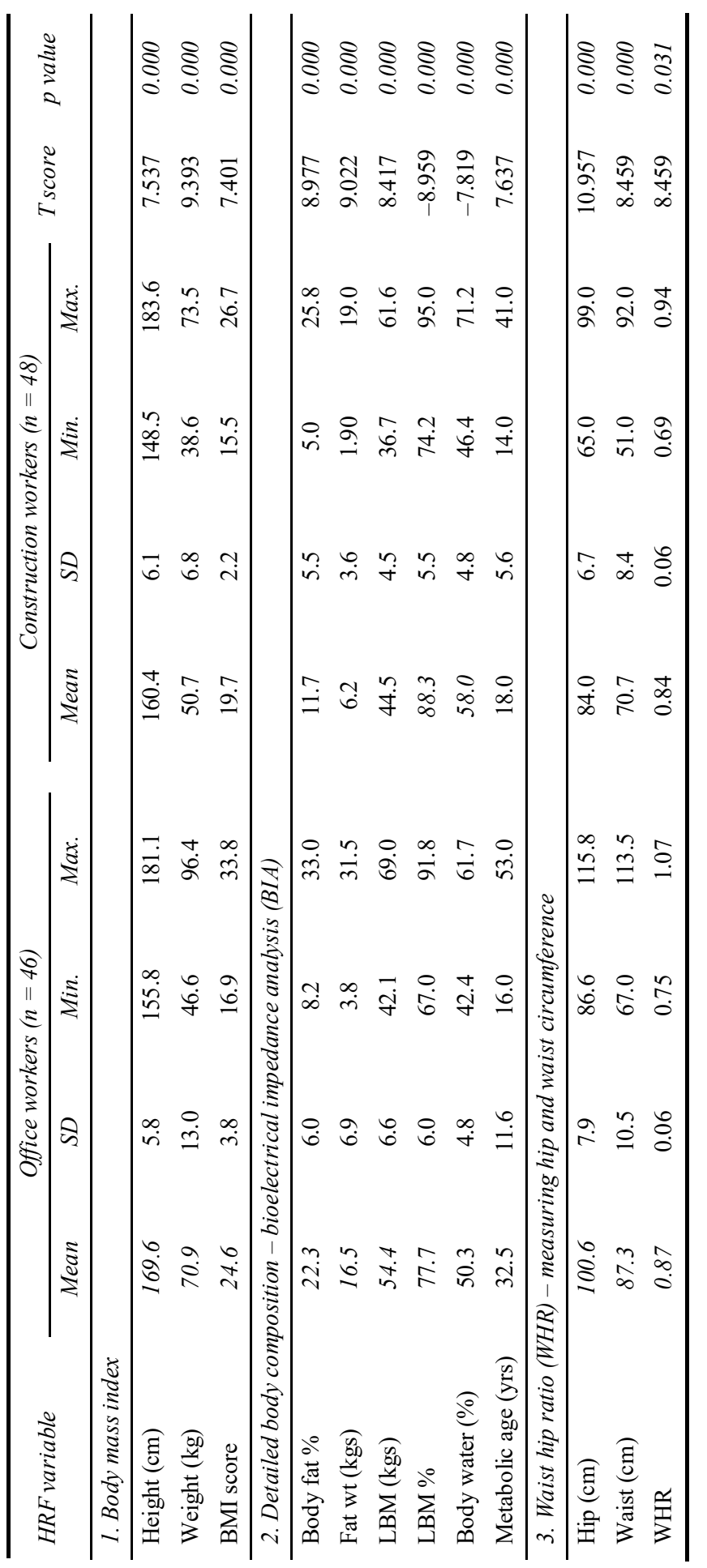


Table 3 Strength, endurance, flexibility and aerobic fitness scores of the workers

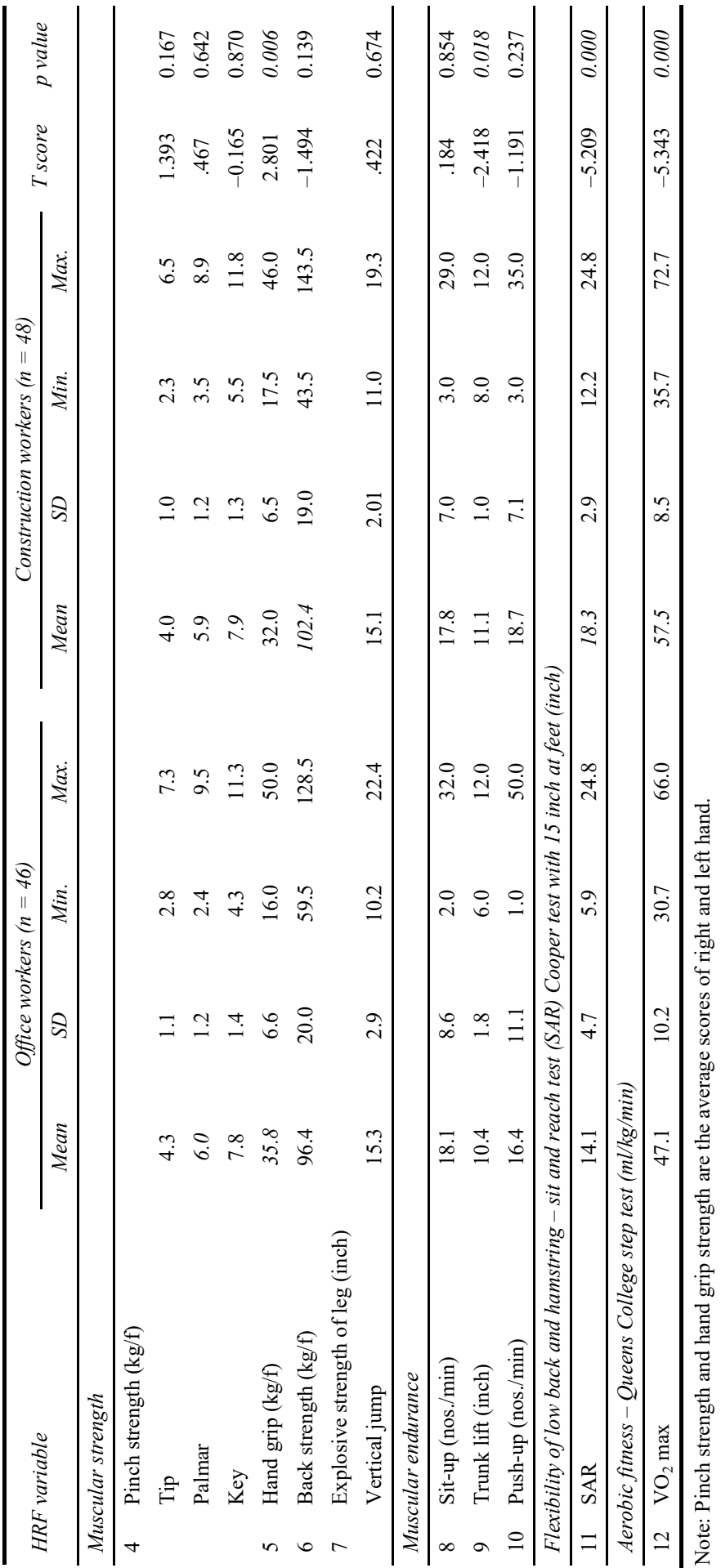


But the other strength parameters like pinch grip strength (at all three locations), back strength and explosive strength of leg were not found to be significantly different between both the groups. Also in muscular endurance test, it can be observed that mean scores of office and construction workers for sit-ups and push-up were not significantly different $(\mathrm{p}>0.05)$. This could be associated with no adequate involvement in strength enhancing activity (at work and outside work) by both the groups; thus, leading to reduced performance (data not included in present study). Also for construction worker, the reduced strength could be due to their daily involvement in moderate to heavy type of physical activity at work, thus reducing their hand strength over a period of time.

However, the average trunk lift scores (11.1 inch), SAR (18.3 inch), and $\mathrm{VO}_{2}$ max $(57.5 \mathrm{ml} / \mathrm{kg} / \mathrm{min})$ was found to be significantly better $(\mathrm{p}<0.05)$ among the construction workers than the office workers, thus representing a substantially enhanced trunk extension endurance, low back flexibility and aerobic fitness (Table 3 ).

For shoulder flexibility (fitness test no. 13), it was found that for 'right hand-up and left down', majority of the office workers (91.3\%) were falling into good-very good category as against only $81.3 \%$ of construction workers falling into good-very good category. But in contrast for shoulder flexibility with 'left hand-up and right down', the construction workers scored better with $77.1 \%$ falling into good-very good category, as compared to only $69.6 \%$ from office workers.

\section{Discussion}

It is apparent from the results that heavy type of construction work is selected mostly as a profession by those people who could not pursue higher education (above 12th grade). Construction workers were shorter in height and lesser in weight but had significantly less BMI scores and fat \% as against the office group. Hip and waist circumference of the construction workers was also significantly lesser indicating less fat deposited at abdominal and hip region. Huang et al. (2017) in a recent study stated that as compared to a low level of occupational PA, a high level of occupational PA represented a significantly lower risk of abdominal adiposity, high triglycerides and lower diastolic blood pressure.

Thus, from present study, it is evident that construction type of occupational work tends to significantly lessen or maintain BMI, fat $\%$, metabolic age and fat deposition at hip and waist region as compared to the office type of sedentary/light work, which is an indicator of better fitness among the construction group. Stamford (2003) also quoted that heavy worker should possess primarily muscle and very little body fat. Availability of decent nutritious food, higher monthly income and least involvement in other type of physical activity during leisure or commuting (data not presented in current paper) could be some of the important factor for increased levels of BMI scores, fat $\%$ and less of LBM \% among the office workers. This could be a matter of concern, as at such an early age there were overweight and obesity related problem among nearly half of the office work population. Wang et al. (2002) stated that overweight and obesity have risen in the last decades among young people.

Hand grip strength $(35.8 \mathrm{~kg} /$ force $)$ was significantly more $(\mathrm{p}<0.05)$ among the office workers but remaining all other strength parameters like pinch grip, back strength, explosive strength of leg and endurance parameters like upper body endurance and core 
body endurance were not significantly different among both the group. Ruzic et al. (2003) found that the subjects with a higher work index performed worse than the subjects with a lower work index on functional and motor abilities. This could be attributed to the fact that physical activity performed at the workplace did not have adequate intensity, volume, and duration to effect positive changes in other motor and functional capacities.

But on the other side, the construction workers were found to have significantly enhanced trunk extension endurance, low back flexibility and aerobic fitness than the office workers. Tammelin et al. (2002) similarly found that men doing heavy physical work scored better in cardio respiratory fitness and trunk muscle endurance; but also higher in handgrip strength (contrasting from the present study) as compared to men doing lighter work. Cureton et al. (2013) indicated that aerobic capacity mostly reflects the level of habitual physical activity, intensity and amount of dynamic, moderate-to-vigorous, sustained (aerobic) physical activity in which one participate. Thus, the occupational activity performed by the construction workers may have altered the above three-fitness parameter by permitting better fitness scores in these tests.

Lesser LBM $(\mathrm{kg})$ could be one of the contributing factors for lesser muscular strength among construction workers as compared to office group. Still the improved performance in back strength test was observed (even though not significant) and this could have related to their need of improved back strength for performing the daily moderate-heavy OPA.

Office workers were observed to be least involved in different type of occupational and non-occupational activity. Thus, muscle strength was found to be more only for hand grip. Even after having decent amount of LBM (kg), still the strength levels among them was not seen to be significantly more than the construction groups. Thus, it can be concluded that mere having more of LBM $(\mathrm{kg})$ does not indicate a higher strength and therefore, one needs to be involved in physical activity to improve the muscular strength. Knaeps et al. (2016) showed that physical activity is related to HRF, regardless of the stability of the physical activity pattern in a healthy adult population. Mwangi and Rintaugu (2017) also found majority of staff members in the institution are not physically active enough and had below the recommended health and fitness status. They recommended an aggressive campaign to educate the staff members on dangers of sedentary lifestyles, and the institutions to embrace prevention-based health policies to prioritise provision of fitness facilities and health promotion programs. PA program can be helpful in improving physical, physiological and psychological outcomes for overweight and sedentary employees in high-tech industries (Fang et al., 2018). Physically demanding jobs can result in negative health and economic related consequences for employees and may also be detrimental for the company and society at large (Bevan et al., 2009). Therefore, physically demanding work may also require a certain level cardio-respiratory fitness and leisure-time physical activity as a means of maintaining or improving fitness level (Holtermann et al., 2010).

\section{Conclusions}

Health and fitness has a direct impact on all activities, economic or otherwise. Measuring health and fitness changes in population is therefore very important, in order to evaluate interventions and to predict the need for health and social care. Physically active workers 
were characterised by a lower level of fat amount, higher flexibility and aerobic fitness; however, sedentary work in office workers can be characterised by overweight and unfit workers. OPA of the construction workers may have attributed with enriched changes in the body composition, flexibility and aerobic fitness parameters; however, sedentary work in office workers may have led to increase in body fat $\%$ and deterioration in their HRF levels.

Muscular fitness which was measured by strength (pinch, back and explosive leg strength) and endurance (upper body and core endurance) were not found to be significantly different among both the group, specifying that the existing occupational activities performed by both the groups did not altered these two fitness parameters. This may be attributed due to very less use of muscles by the office workers and over use of muscular system by the construction workers.

Increased literacy will lead to more of young employees working in office setup, thus making them more sedentary and vulnerable to chronic diseases in their later life. Involvement in physical activity at work can help control the obesity related health issues among the inactive workers. Wellness program can be helpful in improving the strength and endurance components which were not significantly different among both the group.

\section{References}

Anjana, R.M. et al. (2014) 'Physical activity and inactivity patterns in India - results from the ICMR-INDIAB study (phase-1) [ICMR-INDIAB-5]', International Journal of Behavioural Nutrition and Physical Activity, Vol. 11, No. 26, pp.1-11, [online] http://www.ijbnpa.org/content/11/1/26.

Bello, A., Bonney, E. and Opoku, B. (2016) 'Physical fitness of Ghanaian physiotherapists and its correlation with age and exercise engagement: a pilot study', Archives of Physiotherapy, Vol. 6, No. 2, pp.1-5.

Bevan, S., Quadrello, T., McGee, R., Mahdon, M., Vavrosky, A. and Barham, L. (2009) Fit for Work? Musculoskleletal Disorders in the European Workforce, The Work Foundation.

Bray, G.A. and Gray, D.S. (1988) 'Obesity: part 1: pathogenesis', Western Journal of Medicine, Vol. 149, No. 4, pp.429-441.

Caspersen, C.J., Kenneth, P.E. and Gregory, C.M. (1985) 'Physical activity, exercise, and physical fitness: definitions and distinctions for health-related research', Public Health Reports, Vol. 100, No. 2, p.126.

Cooper Institute (2006) Physical Fitness Assessment [online] https://www.tucsonaz.gov/files/ police/CooperStandards.pdf (accessed 27th July 2017).

Cureton, K.J., Plowman, S.A. and Mahar, M.T. (2013) 'Aerobic capacity assessments', in Plowman, S.A. and Meredith, M.D. (Eds.): Fitnessgram/Activitygram Reference Guide, 4th ed., pp.6-1-6-22, internet resource, The Cooper Institute, Dallas, TX.

Cvejic, D., Pejovic, T. and Ostojic, S. (2013) 'Assessment of physical fitness in children and adolescents', Physical Education and Sport, Vol. 11, No. 2, pp.135-145.

Fang, Y.Y., Huang, C.Y. and Hsu, M.C. (2018) 'Effects of physical activity program on weight, physical fitness, occupational stress, job satisfaction, and quality of life of overweight employees in high-tech industries: a randomized controlled study', International Journal of Occupational Safety and Ergonomics, DOI: 10.1080/10803548.2018.1438839.

Hallal, P.C., Andersen, L.B., Bull, F.C., Guthold, R., Haskell, W. and Ekelund, U. (2012) 'Global physical activity levels: surveillance progress, pitfalls, and prospects', Lancet, Vol. 380, No. 9838, pp.247-257. 
Hill, J.O. and Melanson, E.L. (1999) 'Overview of the determinants of overweight and obesity: current evidence and research issues', Med. Sci. Sports Exerc., Vol. 31, No. 11, pp.S515-S521.

Holtermann, A., Mortensen, O.S., Burr, H., Sogaard, K., Gyntelberg, F. and Suadicani, P. (2010) 'Physical demands at work, physical fitness, and 30-year Ischaemic heart disease and all-cause mortality in the Copenhagen male study', Scand. J. Work Environ. Health, Vol. 36, No. 5, pp.357-365.

Huang, J.H., Li, R.H., Huang, S.L., Sia, H.K., Lee, S.S., Wang, W.H. and Tang, F.C. (2017) 'Relationships between different types of physical activity and metabolic syndrome among Taiwanese workers', Scientific Reports, Vol. 7, No. 13735, pp.1-8, DOI: 10.1038/s41598017-13872-5.

Huotari, P. (2012) Physical Fitness and Leisure-time Physical Activity in Adolescence and in Adulthood: A 25-year Secular Trend \& Follow-up Study, LIKES - Research Center for Sport $\&$ Health Sciences, Jyvaskyla.

Kaasalainen, K.S., Kasila, K., Villberg, J, Komulainen, J. and Poskiparta1, M. (2013) 'A cross-sectional study of low physical fitness, self-rated fitness and psychosocial factors in a sample of Finnish 18- to 64-year-old men', BMC Public Health, Vol. 13, No. 1113, pp.1-10.

Knaeps, S., Bourgois, J.G., Charlier, R., Mertens, E. and Lefevre, J. (2016) 'Associations between physical activity and health-related fitness - volume versus pattern', Journal of Sports Sciences, DOI: 10.1080/02640414.2016.1178393.

Kopiczko, A. and Bogucka, A. (2018) 'Assessment of total fatness and fatty tissue distribution in young active and physically inactive women', Biomedical Human Kinetics, Vol. 10, No. 1, pp.38-44, DOI: https://doi.org/10.1515/bhk-2018-0007.

Luzak, A., Heier, M., Thorand, B., Laxy, M., Nowak, D., Peters, A. et al. (2017) 'Physical activity levels, duration pattern and adherence to WHO recommendations in German adults', PLoS ONE, Vol. 12, No. 2, pp.1-15, DOI: 10.1371/journal.pone.0172503.

McArdle, W.D. et al. (1972) 'Reliability \& interrelationships between maximal oxygen uptake, physical work capacity \& step test scores in college women', Medicine \& Science in Sports, Vol. 4, No. 4, pp.182-186.

Ministry of Youth Affairs \& Sports (2012) Exposure Draft on National Physical Fitness Programme for School Children, Department of Sports, Shastri Bhawan, New Delhi, Government of India.

Mwangi, F.M. and Rintaugu, E.G. (2017) 'Physical activity and health related physical fitness attributes of staff members in a Kenyan public university', International Journal of Sports Science, Vol. 7, No. 2, pp.81-86, DOI: 10.5923/j.sports.20170702.09.

Plowman, S.A. and Meredith, M.D. (Eds.) (2013) Fitnessgram/Activitygram Reference Guide, 4th ed., The Cooper Institute, Dallas, TX.

Ruiz, J.R., Castro-Piñero, J., Artero, E.G., Ortega, F.B., Sjöström, M., Suni, J. et al. (2009) 'Predictive validity of health-related fitness in youth: a systematic review', British Journal of Sports Medicine, Vol. 43, No. 12, pp.909-923.

Ruzic, L., Heimer, S., Misigoj-Durakovic, M. and Matkovic, B. (2003) 'Increased occupational physical activity does not improve physical fitness', Occup. Environ. Med., Vol. 60, No. 12, pp.983-985.

Shin, J.I., Park, S.J., Yang, D.J. et al. (2012) 'Improvement or work ability by exercise program', J. Phys. Therapy Sci., Vol. 24, No. 11, pp.1111-1113.

Stamford, B.A. (2003) Physical Fitness Preparation Guidelines and Physical Ability Test Overview for Fire Fighter Applicants, Fitness Preparation Manual, Louisville Metro Civil Service and Louisville Fire \& Rescue.

Suni, J., Husu, P. and Rinne, M. (2009) Fitness for Health: The ALPHA FIT Test Battery for Adults Aged 18-69. Testers Manual. European Union, DG Sanco and The UKK Institute for Health Promotion Research, Tampere, Finland [online] http://www.ukkinstituutti.fi/filebank/500ALPHA_FIT_Testers_Manual.pdf (accessed 15th July 2017). 
Tammelin, T., Näyhä, S., Rintamäki, H. and Zitting, P. (2002) 'Occupational physical activity is related to physical fitness in young workers', Med. Sci. Sports Exerc., Vol. 34, No. 1, pp. $158-165$.

Voit, S. (2001) 'Work-site health and fitness programs: impact on the employee and employer', Work: A Journal of Prevention, Assessment and Rehabilitation, Vol. 16, No. 3, pp.273-286, IOS Press.

Wang, Y., Monteiro, C. and Popkin, B.M. (2002) 'Trends of obesity and underweight in older children and adolescents in the United States, Brazil, China, and Russia', Am. J. Clin. Nutr., Vol. 75, No. 6, pp.971-977.

World Health Organisation (2010) Estimated Overweight and Obesity (BMI > $\left.25 \mathrm{~kg} / \mathrm{m}^{2}\right)$ Prevalence, Males, Aged 15+, The WHO Global Infobase [online] https://apps.who.int/ infobase/Index.aspx (accessed 5th November 2012). 